\title{
25 Years Ago in the \\ Canadian Journal of Neurological Sciences
}

\author{
The Anatomical Substratum of Pain Evidence Derived from \\ Morphometric Studies on Peripheral Nerve
}

\author{
P.K. Thomas
}

SUMMARY: Earlier theories as to the anatomical basis of pain postulated a direct 'pain pathway' from specific receptors in the periphery. Anatomical studies linked this with small myelinated and unmyelinated fibers in the peripheral nerves. Subsequently, hypotheses were advanced which postulated that pain depended upon particular spatial and temporal patterns of sensory input into the nervous system rather than upon specific sets of fibers.

Most recent physiological studies have demonstrated the existence of peripheral receptors that respond exclusively to noxious stimuli and morphometric studies on peripheral neuropathies in man clearly implicate small myelinated and unmyelinated axons in the conduction of pain. Morphometric studies have also shown that spontaneous pain in neuropathies may be associated with a selective loss of small fibers. These observations therefore support the earlier concept of a specific nociceptive pathway involving small caliber fibers in the peripheral nerves. It is evident that this afferent pathway is capable of modification in the spinal cord both by peripheral inputs and by descending impulses. The notion of a 'pain pathway' as such is probably best avoided.

Can. J. Neurol. Sci. 1974; 2:92

\section{Cytoplasmic Tubular Aggregates and Nuclear Filamentous Bodies in Two SusPected CASES OF Viral ENCEPHalitis}

\section{Dikran S. Horoupian, R. T. Ross,}

Mark J. Gurwith, Jan Hoogstraten

SUMMARY: Two suspected cases of viral encephalitis are presented. Viral nucleocapsids were not seen, but cytoplasmic paramyxovirus-like aggregates and nuclear filamentous bodies were frequently encountered. Both structures were seen in the same cell. Contrary to other reports, the cytoplasmic aggregates were mostly observed in hematogenous mononuclear cells, less frequently in neuronal cell elements and rarely in endothelial cells. The non-specific nature of these structures is emphasized.

Can. J. Neurol. Sci. 1974; 2:98

\section{Chronic Benign Congenital Myopathy: Fingerprint Body Type}

\section{A. S. Gordon, N. B. Rewcastle, \\ J. G. Humphrey, B. M. Stewart}

SUMMARY: The term "benign congenital myopathy" describes a group of muscle disorders characterized by proximal or diffuse muscle weakness, a relatively non-progressive course, normal serum muscle enzyme assays and the presence of a distinctive morphological feature. We report here a 55 year old woman, with fingerprint body myopathy who exhibits all of the above features. She has been affected from birth, able to walk since the age of 12 , and has not deteriorated in the past thirty years. Muscle biopsy reveals fatty infiltration, numberous small fibers undergoing structural change, good differentiation into type I and II fibers, and excessive intracellular lipid and lipochrome. Only on electron microscopic study is the distinctiive feature of numerous subsarcolemmal round to ovoid fingerprint bodies observed. Many fibers also contain large collections of tubular aggregates, filamentous bodies, and autophagic vacuoles.

The fingerprint bodies are similar to the ones described by A. Engelin in a 5 year old girl. Thus, a rare opportunity is provided to study an individual who has had this disease for over fifty years.

Can. J. Neurol. Sci. 1974; 2:106 


\title{
25 Years Ago in the \\ Canadian Journal of Neurological Sciences
}

\author{
TOXOCARA CANIS INFESTATION WITH ENCEPHALITIS \\ Nadia Z. Mikhael, Vital J. A. Montpetit, Manuel Orizaga \\ Harry C. Rowsell, Michael T. Richard
}

SUMMARY: The syndrome "visceral larva migrans" produced by migration of nematode larvae (commonly Toxocara species) in the extraintestinal tissues in unusual hosts, including man (particularly children of dirt eating age), with the production of reactive granulomatous lesions, was first described in 1952. About 200 cases have been reported since. Well documented cases are rare due to the difficulty in histological verification. Three cases have been reported in Canada but these were not verified. We believe the present report is the first verified case of visceral larva migrans in Canada and the fifth case of human cerebral involvement by toxocara in the English literature. It is hoped that this report will emphasize the need for further research into the role of host versus parasite and will underline the potential danger, albeit remote, of household pets to children. Indeed, prevention is the only line of attack, as there is no effective drug against the migrating larvae of Toxocara.

\section{Rete Mirable - The Marvellous Network Dwight Parkinson}

SUMMARY: The anastomotic channels found about the base of the brain in the presence of internal carotid inadequacy are not properly termed a rete mirable.

Can. J. Neurol. Sci. 1974; $2: 121$

\section{TRaumatic Infaction OF THE SPINAL CORD}

\section{W. S. Keith}

SUMMARY: Infarction of the spinal cord is an occasional complication of thoracic and aortic surgery and dissecting aneurysm. Only once has it been reported following injury. This paper recounts the histories of four children each of whom survived an automobile accident; each with permanent paraplegia due to infarction.

Can. J. Neurol Sci. 1974; 2:124

Can. J. Neurol. Sci. 1974; 2-114

\section{MYASTHENIA GRAVIS ASSOCIATED WITH DIPHENYLHYDANTOIN THERAPY FOR EPILEPSY}

Joel Brumlik, Robert S. Jacobs

SUMMARY: A young woman with epilepsy developed myasthenic symptoms while taking diphenylhydantoin. The clinical, electromyographic and pharmacologic findings were consistent with myasthenia gravis. Symptoms of myasthenia ceased on withdrawal of the drug, and recurred on readministration, with little apparent relationship to serum phenytoin levels. This unusual effect is discussed with reference to the known effects of diphenylhydantoin at the neuromyal junction.

Can. J. Neurol. Sci. 1974; 2:127 


\title{
25 Years Ago in the Canadian Journal of Neurological Sciences
}

\author{
Wohlfart Kugelberg Welander Syndrome \\ R. T. Ross, Charles A. Simpson, Salma Styles
}

SUMMARY: A family is described with two brothers suffering from the Wohlfart Kugelberg Welander syndrome and seven unaffected siblings. Another brother died in infancy from "a spinal disorder". Both affected males developed symptoms in the third decade with weakness of the lower limb girdle, followed by the upper limb girdle. Both showed fasciculations, hyporeflexia and purely lower motor neuron findings. EMG showed evidence of denervation and muscle biopsy showed neurogenic atrophy. Terminal motor latencies were slightly prolonged and one showed an elevated serum aldolase while both had elevated C.P.K.'s. Laboratory studies on some of the normal siblings were normal. The younger brother who has been seen over two years seems to have become slightly stronger.

Dermatoglyphics and chromosomal analysis have been carried out on the patients and some of the normal siblings. All were normal except for the younger affected brother who has persistently showed a high percentage of abnormal cells, though the basic karyotype was normal, and abnormal dermatoglyphics.

This is the only case we have found in the literature with chromosome abnormalities. This pedigree suggests a recessive inheritance, possibly $\mathrm{x}$ linked.

Can. J. Neurol. Sci. 1974; 2:130

\section{口an \\ WEATHERBEE AIL \\ Documention of a Neurological Disease in a Vermont Family 90 Years Later \\ James M. Powers, Dikran S. Horoupian, Herbert H. Schaumburg}

SUMMARY: The neuropathological findings of a Farr family member consist of neuronal loss in the anterior horns and dorsal nuclei of Clarke, neuronal intracytoplasmic inclusions and posterior and lateral column demyelination. This report supports the role of familial amyotrophic lateral sclerosis as a link between common motor neuron disease and classical spinocerebellar degeneration.

Can. J. Neurol. Sci. 1974; 2:139

\section{A ReVIEw of ACRYlamide Neurotoxicity Part I: Properties, Uses and Human Exposure \\ Peter S. Spencer, Herbert H. Schaumburg}

SUMMARY: Two factors have stimulated the present intense investigation of acrylamide neurotoxicity. These are the health hazard accompanying the vast and increasing industrial production of acrylamide, and the promise of illuminating the mechanism of dying-back disease in the human nervous system by employing acrylamide as an experimental tool. The present paper discusses the industrial uses of acrylamide, its regulation and the prevention, detection and clinico-pathologic features of human intoxication. Bearing on the cumulative nature of acrylamide neurotoxicity, separate sections review the chemistry, biochemistry, toxicology and metabolic fate of acrylamide. Clinical, electrophysiological and morphologic data on acute and chronic acrylamide intoxication of experimental animals, and possible etiologies of nervous system damage, are considered in detail in a companion paper (P. S, Spencer and H. H. Schaumburg, Canadian Journal of Neurological Sciences, 1:151, 1974.)

Can. J. Neurol. Sci. 1974; 2:143 